\title{
Current Evidence in Gastrointestinal Surgery: Natural Orifice Translumenal Endoscopic Surgery (NOTES)
}

\author{
Deborah S. Keller • Conor P. Delaney
}

Received: 4 June 2013 / Accepted: 24 June 2013 / Published online: 17 July 2013

(C) 2013 The Society for Surgery of the Alimentary Tract

\begin{abstract}
Background Natural orifice translumenal endoscopic surgery (NOTES) is a technique that uses transvisceral access to perform surgical procedures entirely through a natural orifice. Despite the increasing awareness of NOTES, there remain obstacles to its technical feasibility and widespread acceptance. Furthermore, with the paucity of high-level supporting evidence, NOTES currently remains an experimental technique.

Objective This article reviews the goals, applications, technical and practical challenges, and future direction of NOTES in gastrointestinal surgery.
\end{abstract}

Keywords Natural orifice translumenal endoscopic surgery (NOTES) $\cdot$ Minimally invasive surgery

\begin{tabular}{|c|c|}
\hline \multicolumn{2}{|l|}{ Abbreviations } \\
\hline ASGE & $\begin{array}{l}\text { American Society for Gastrointestinal } \\
\text { Endoscopy }\end{array}$ \\
\hline MA-NOS & $\begin{array}{l}\text { Minilaparoscopic-assisted natural orifice } \\
\text { surgery }\end{array}$ \\
\hline NOTES & $\begin{array}{l}\text { Natural orifice translumenal endoscopic } \\
\text { surgery }\end{array}$ \\
\hline NOSE & Natural Orifice Specimen Extraction \\
\hline NOSCAR & $\begin{array}{l}\text { Natural Orifice Surgery Consortium For } \\
\text { Assessment And Research }\end{array}$ \\
\hline PROGRESSS & $\begin{array}{l}\text { Perirectal oncologic gateway for retroperi- } \\
\text { toneal endoscopic single-site surgery }\end{array}$ \\
\hline SAGES & $\begin{array}{l}\text { Society of American Gastrointestinal and } \\
\text { Endoscopic Surgeons }\end{array}$ \\
\hline TAMIS & Transanal minimally invasive surgery \\
\hline TEM & Transanal endoscopic microsurgery \\
\hline
\end{tabular}

\section{Background}

Natural orifice translumenal endoscopic surgery (NOTES) was heralded as a paradigm shift in minimally invasive surgery. In

\section{S. Keller · C. P. Delaney $(\bowtie)$}

Division of Colorectal Surgery, Department of Surgery, University

Hospitals Case Medical Center, Case Western Reserve University,

11100 Euclid Ave., Cleveland, OH 44106-5047, USA

e-mail: Conor.Delaney@uhhospitals.org
NOTES, procedures may be performed through transvaginal, transgastric, transrectal, or transesophageal approaches. NOTES was originally described by Kalloo et al. in 2004 as a peroral transgastric approach to access the peritoneal cavity for a liver biopsy in a porcine model. ${ }^{1}$ The initial report attracted widespread interest from both surgeons and gastroenterologist worldwide. Within a year, Reddy and Rao reported the first human transgastric appendectomy at the Annual Conference of the Society of Gastrointestinal Endoscopy of India. ${ }^{2}$ Numerous investigators followed suit, using NOTES in animal models to perform a variety of intraperitoneal procedures, including cholecystectomy, colectomy, and distal pancreatectomy. ${ }^{3-7}$ By 2007, Swanstrom et al. reported the first successful human NOTES procedure- a transgastric cholecystectomy. ${ }^{8}$

\section{Goals}

The goal of NOTES was to provide a technology for potentially scar-free surgery and abolishment of incision-related complications, such as such as wound infections, incisional hernias, postoperative pain, and adhesions. ${ }^{9}$ Patient and surgeon desire for a surgical technique that provided reduced recovery time, physical pain, and scarring over available minimally invasive approaches provided momentum for NOTES research and expansion. ${ }^{10}$ Wound infections are reported to occur in $2-25 \%$ of surgical procedure and have a significant impact on patient outcomes and health-care expenditures. ${ }^{11^{-13}}$ While minimally invasive surgery decreased the incisional 
hernia rate dramatically, NOTES introduced the ability to eliminate all incisions and subsequent incisional hernias (Fig. 1). ${ }^{14}$

\section{Application of NOTES}

NOTES has been extensively applied and tested in animal and cadaver models. Since the first description, more than 2,000 reports of NOTES across all surgical specialties have been described. A PubMed $\odot$ search of NOTES from 2004 to the present yielded over 600 publications, with more than half published in general surgery journals $(50.9 \%) .{ }^{15}$ The transgastric, transrectal, transcolonic, transanal, transvesical, and transesophageal approaches have been feasible for a variety of procedures, including cholecystectomy, hepatectomy, splenectomy, nephrectomy, gastrojejunostomy, gastric sleeve resection, tubal ligation, distal pancreatectomy, and colectomy. However, most published studies remain clinical series $(43.9 \%)$ and experimental animal reports $(48 \%)$, with the articles focusing primarily on cholecystectomy, access creation/closure, and peritoneoscopy. ${ }^{15}$

With the abundance of safety and feasibility studies, the question remains why NOTES has not progressed further into clinical practice. In humans, only about 43 reports covering 432 NOTES cases have been reported. ${ }^{16}$ Cholecystectomy $(84 \%)$ and appendectomy (7\%) were the most popular procedures reported. Meta-analysis and single-center studies of NOTES procedures in human patients found that cholecystectomy, intestinal cancers, renal cancers, appendectomy, mediastinoscopy, and peritoneoscopy were all feasible with NOTES with low postoperative complication rates, no visible scars, and lower analgesia requirements. ${ }^{16-20}$ However, the technical complications encountered demonstrated the need of developing endoscopic instruments to safely facilitate each approach. ${ }^{17}$

To encourage NOTES research and outline areas to further the human application of NOTES, the collaborative

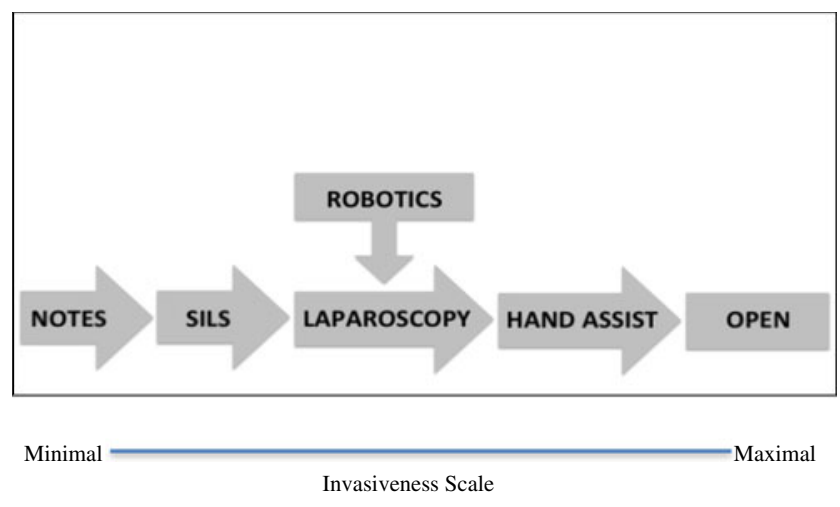

Fig. 1 Minimally invasive scale of surgical procedures
Natural Orifice Surgery Consortium For Assessment And Research (NOSCAR) working group was formed from the SAGES and the ASGE. ${ }^{10}$

\section{Technical Challenges}

NOSCAR identified unresolved technical issues in NOTES, including how to access the peritoneal cavity, viscerotomy closure, suturing/anastomotic devices, spatial orientation, developing a multitasking operating platform, managing complications, and effective training. ${ }^{10}$ There is no "best practice" to access the peritoneal cavity. Current major routes described in all reports include transgastric (52.5\%), transcolonic (12.3\%), transvesical (12.5\%), transvaginal $(10.5 \%)$, and combined $(12.3 \%){ }^{15}$ In human subjects, the main access routes were transvaginal $(84 \%)$, transgastric (13\%), transesophageal $(4 \%)$, and transrectal $(<1 \%) .{ }^{16}$ The transgastric approach uses endoscopic balloon dilatation, sphincterotome, or needle knife cautery to create and dilate a hole on the anterior stomach wall for introduction of the operating platform. However, there is a risk of injuring surrounding organs blood vessels during the blind puncture, as well as devastating consequences from a leak. There have been entry assists described in animal models, including endoscopic ultrasound or invaginating the gastric wall to distract from surrounding organs, but the efficacy in human subjects is not described. ${ }^{21-23}$

The transvaginal approach has been successfully used in the diagnosis of endometriosis, adhesions, and ectopic pregnancy. It has the advantage over other access methods that the incision can be achieved under direct visualization without an intra-abdominal scope. ${ }^{16}$ However, this approach requires working deep in the pelvis and is only applicable in $50 \%$ of the population. Further, there is the risk of injuries to the rectum, ureters, bladder, and colon while obtaining access or closing the posterior vaginal wall given its proximity to these structures. ${ }^{16}$ With the transvesical approach, the major limitation is working against the long male urethra. Both the transvaginal and transvesical approaches have a potential reduction in morbidity compared to transgastric access. The transrectal approach, facilitated with a stable transanal endoscopic microsurgery (TEM) platform or performed through direct transrectal trocar insertion, allows direct access to upper quadrants without retroflexion and permits removal of large specimens and the use of operating anoscopes for secure closure. ${ }^{24-26}$ However, there is a risk of closure leak and need for better NOTES instrumentation before widespread clinical application. Further research is underway with the PROGRESSS study. ${ }^{27}$ Each approach has its pros and cons, and all require development of best practices and improved instrumentation.

Studies on safer alternatives for access are underway. Elmunzer et al. evaluated the utility of sonographic guidance 
for safe intraperitoneal access during the initial NOTES puncture. $^{28}$ In a porcine feasibility study, 32 sonographicguided access procedures were performed through the antrum, posterior stomach wall, or rectum, of which 16 used sonographic guidance for safe intraperitoneal access by avoiding extraluminal organs and vessels during the initial puncture and 16 using standard NOTES blind puncture to evaluate potential complications. All 16 blind NOTES access procedures had clinically catastrophic complications, while only three sonographic-guided procedures had complications. Thus, sonographic guidance significantly decreased complications during access and may be a promising addition to developing safe standards for peritoneal access.

The optimal visceral closure technique after NOTES is also under development. A closure device must create a fullthickness, tension-free closure. The ideal tool must also be easy to use, applicable to multiple organs, reproducible, reliable, and safe. Current options include clips, endoscopic tubes, $\mathrm{T}$ fasteners, endoscopic suturing devices, and novel closure devices, such as the Spiderman. It is necessary that the closure device provides a nearly $100 \%$ secure closure of the enterotomy site, as a leak rate of even $1 \%$ would be unacceptable with the low leak rates of laparoscopy. ${ }^{29}$ To date, viscerotomy closure has not been achieved reliably in humans, and the subsequent risk of peritoneal infection remains a valid concern. ${ }^{30}$

The tissue apposition system (TAS) may be a promising device for endoscopic suturing. In human subjects, TAS was feasible as an alternative to laparoscopic colectomy for endoscopically unresectable polyps. The device could be expanded to facilitate closure of larger defects from NOTES procedures. ${ }^{31}$

The current NOTES instruments and endoscopes are another technical limitation. A variety of laparoscopic instruments exist for hybrid NOTES with a transabdominal port, but flexible endoscopic instrumentation is much more limited. The available tools limit visualization, successful completion of the procedure compared to laparoscopy, and evolution of NOTES. ${ }^{32}$ There is also no standardization of the available endoscopes or instruments. The choice of endoscope and dissection tools utilized differs greatly between pure NOTES, hybrid procedures, and access routes, with wide variation even within the same procedure and access method. ${ }^{16,33}$ Current research on developing instruments to aid performing pure NOTES is underway. ${ }^{34,35}$ For further incorporation into humans, fundamental steps and elements present in all procedures, as well as practical and technical challenges, will need to be resolved.

NOTES also introduces ergonomic challenges to surgeons. With no standardization in technique, ergonomic studies of NOTES cholecystectomy have shown that surgeons were uniquely limited in visualization, tissue manipulation, and in the ability to independently perform tasks, requiring collaboration to safely complete NOTES procedures. ${ }^{36}$

The small number of procedures precludes an accurate estimate of the actual complication rates or analysis of contributing factors. Thus, it remains to be determined whether complications associated with NOTES are a result of an early learning curve or inherent procedure and likely to occur at unacceptable rates even after ascension up the learning curve. ${ }^{16}$ Standardization in technique and reporting, as well as large-scale prospective trials, is necessary for proper analysis of outcomes and complications.

\section{Practical Challenges}

Developing a training platform and training providers to teach and use NOTES is another technical hurdle. For NOTES to become a common surgical approach, multiple training platforms are needed for success. Options for success include a hands-on training experience in a simulated environment, close monitoring of surgeon performance with both thermal imaging and motion tracking to ensure proper technique and confirm procedural competence, and mentoring through their initial procedures. ${ }^{37-39}$ Combining advanced imaging technologies with proficiency-based virtual reality simulation is a feasible alternative to animal testing once the safety and efficacy parameters of NOTES are established. ${ }^{40}$ In a study on training techniques with currently available instruments for transgastric procedures, technical limitations impacted learning, with problems encountered including intraesophageal friction, lack of platform stability, lack of precision in tissue retraction, and lack of independence of endoscopic vision; the technical problems were more limiting than procedural or medical knowledge. ${ }^{41}$

Steep learning curves are encountered when attempting to introduce NOTES into training programs, despite the availability of experienced NOTES investigators. ${ }^{42}$ While education remains in development, studies have shown that most surgeons desired training in NOTES, and almost all would perform NOTES if further research showed demonstrable benefits. Building on existing platforms may aid learning and teaching. TEM has been described as the ideal NOTES platform for endoscopic access of the peritoneal cavity through the anus. ${ }^{25}$ Using the combination of established TEM and NOTES principles, colorectal resections could be performed through smaller or no abdominal incisions. Trunzo and Delaney used the combination to perform a novel proctectomy technique in a porcine model. ${ }^{43}$ The circumferential rectal sleeve resection was safe and feasible using TEM with flexible endoscopic assistance. After extensive cadaver and animal lab experience, NOTES transanal endoscopic rectosigmoid resection with total mesorectal excision using the TEM platform and laparoscopic assistance was also shown to be safe and oncologically sound in a human rectal cancer patient. $^{24,25}$ Based on these experiences, marrying techniques could further education, case complexity, and spread clinical application of NOTES. 
Both surgeon and public attitude toward NOTES have influenced its adaption. While patients desire improved cosmesis and less pain, major concerns about infection, incisional hernias, dyspareunia, and postoperative sexuality and fertility, especially with the transvaginal approach, outweigh advantages of NOTES. ${ }^{44-48}$ Studies show that patients would consider NOTES only if there was no additional risk, pain, operative time, or cost over laparoscopy. ${ }^{49}$ Interestingly, procedure-related risks, pain, and recovery time were more important to patients than cosmesis in the choice of approach. ${ }^{49,50}$ Surgeons' acceptance of NOTES, both for their patients and their own care, is still lacking. In a survey of over 350 surgeons comparing NOTES to laparoscopy for cholecystectomy, NOTES was reported as riskier and requiring greater skill. Only $24 \%$ would undergo a NOTES cholecystectomy themselves, finding it too new and riskier than laparoscopy. As the risk of having a complication was paramount, the majority $(88 \%)$ required data showing improved outcomes over laparoscopy to adapt NOTES. ${ }^{51}$

\section{Future Direction}

Variations in NOTES have been implemented to increase use of the technique. While pure NOTES uses only an endoscope, hybrid NOTES uses both an endoscope and a laparoscope, facilitating an additional view, intraoperative traction of organs, and the familiar laparoscopic techniques, which can help the transition to NOTES. ${ }^{52,53}$ Minilaparoscopy-assisted natural orifice surgery (MA-NOS) uses the principles of laparoscopic surgery for transrectal colorectal resections. ${ }^{54-56}$ In preliminary studies, MA-NOS has been safe and feasible and may aid safe progression to pure NOTES for providers experienced in laparoscopic surgery. Natural orifice specimen extraction (NOSE) has been used for transanal and transvaginal specimen extraction during laparoscopic colorectal surgery. ${ }^{57}$. In 179 anterior resections in rectal cancer patients, Franklin et al. found NOSE safe, feasible, and valuable in reducing incisional complication risks while maintaining proper oncologic principles. ${ }^{58}$ Therefore, it may be a bridge towards NOTES. ${ }^{59}$ Transanal minimally invasive surgery (TAMIS), a hybrid of TEM and singleport laparoscopy, was developed and proven as an efficacious tool for resection of malignant and benign rectal lesions. ${ }^{60}$ Since development, the range of procedures successfully approached through a TAMIS approach have grown. ${ }^{61,62}$, and techniques combining endoscopic visualization with TAMIS to facilitate intraluminal articulation and visualization have been reported. ${ }^{63}$ These techniques show the evolution in minimally invasive surgery.

The cost-benefit analysis of this emerging technology is also an issue that deserves consideration in the current healthcare market. There are increased costs associated with the development and learning acquisition of any new technique.
Once providers are efficient in NOTES, the procedure has the potential to reduce length of stay, postoperative complications, readmissions, and their associated health-care costs.

\section{Conclusions}

The potential for NOTES technology is endless. However, with the current literature and application, no conclusions can be drawn about the overall safety, efficacy, or superiority of NOTES in surgery. ${ }^{15}$ To assure that the technology is effective and efficient, the future of NOTES requires careful laboratory investigation with subsequent IRB-approved clinical trials. Appropriate equipment development and standardized methods of visceral entry and closure would aid acceptance of NOTES. Finally, standardized training programs and short-term cost and outcome analysis would help the new technology integrate into clinical application. Current needs for success are clinical trial, cost-benefit analysis, and standardized training programs. Additional research detailing long-term outcomes, safety, feasibility, and superiority over current minimally invasive techniques in human subjects is needed to further the clinical adaption of NOTES initially set forth by the NOSCAR committee.

\section{References}

1. Kalloo AN, Singh VK, Jagannath SB et al. Flexible transgastric peritoneoscopy: a novel approach to diagnostic and therapeutic interventions in the peritoneal cavity. Gastrointest Endosc. 2004;60:114 117.

2. Reddy N, Rao P. Per oral transgastric endoscopic appendectomy in human. 45th Annual Conference of the Society of Gastrointestinal Endoscopy of India. 2004

3. Bergstrom M, Ikeda K, Swain P, Park PO. Transgastric anastomosis by using flexible endoscopy in a porcine model (with video). Gastrointest Endosc. 2006;63:307-312.

4. Kantsevoy SV, Jagannath SB, Niiyama H et al. Endoscopic gastrojejunostomy with survival in a porcine model. Gastrointest Endosc. 2005;62:287-292.

5. Kantsevoy SV, Hu B, Jagannath SB et al. Transgastric endoscopic splenectomy: is it possible? Surg Endosc. 2006;20:522-525.

6. Park PO, Bergstrom M, Ikeda K, Fritscher-Ravens A, Swain P. Experimental studies of transgastric gallbladder surgery: cholecystectomy and cholecystogastric anastomosis (videos). Gastrointest Endosc. 2005;61:601-606.

7. Wagh MS, Merrifield BF, Thompson CC. Endoscopic transgastric abdominal exploration and organ resection: initial experience in a porcine model. Clin Gastroenterol Hepatol. 2005;3:892-896.

8. USGI Medical, Inc. USGI Medical Announces first NOTES Transgastric Cholecystectomy Procedures Performed by Dr. Lee Swanstrom at Legacy Hospital. 2007

9. McGee MF, Rosen MJ, Marks J et al. A primer on natural orifice transluminal endoscopic surgery: building a new paradigm. Surg Innov. 2006;13:86-93. 
10. Rattner D, Kalloo A. ASGE/SAGES Working Group on Natural Orifice Translumenal Endoscopic Surgery. October 2005. Surg Endosc. 2006;20:329-333.

11. Bratzler DW, Houck PM. Antimicrobial prophylaxis for surgery: an advisory statement from the National Surgical Infection Prevention Project. Clin Infect Dis. 2004;38:1706-1715.

12. DiPiro JT, Martindale RG, Bakst A, Vacani PF, Watson P, Miller MT. Infection in surgical patients: effects on mortality, hospitalization, and postdischarge care. Am J Health Syst Pharm. 1998;55:777-781.

13. Kirkland KB, Briggs JP, Trivette SL, Wilkinson WE, Sexton DJ. The impact of surgical-site infections in the 1990s: attributable mortality, excess length of hospitalization, and extra costs. Infect Control Hosp Epidemiol. 1999;20:725-730.

14. Montz FJ, Holschneider CH, Munro MG. Incisional hernia following laparoscopy: a survey of the American Association of Gynecologic Laparoscopists. Obstet Gynecol. 1994;84:881-884.

15. Autorino R, Yakoubi R, White WM et al. Natural orifice transluminal endoscopic surgery (NOTES): where are we going? A bibliometric assessment. BJU Int. 2013;111:11-16.

16. Auyang ED, Santos BF, Enter DH, Hungness ES, Soper NJ. Natural orifice translumenal endoscopic surgery (NOTES $\left.\left({ }^{\circledR}\right)\right)$ : a technical review. Surg Endosc. 2011;25:3135-3148.

17. Moris DN, Bramis KJ, Mantonakis EI, Papalampros EL, Petrou AS, Papalampros AE. Surgery via natural orifices in human beings: yesterday, today, tomorrow. Am J Surg. 2012;204:93-102.

18. Zornig C, Mofid H, Emmermann A, Alm M, von Waldenfels HA, Felixmuller C. Scarless cholecystectomy with combined transvaginal and transumbilical approach in a series of 20 patients. Surg Endosc. 2008;22:1427-1429.

19. Zorron R, Palanivelu C, Galvao Neto MP et al. International multicenter trial on clinical natural orifice surgery-NOTES IMTN study: preliminary results of 362 patients. Surg Innov. 2010;17:142-158.

20. Targarona EM, Gomez C, Rovira R et al. NOTES-assisted transvaginal splenectomy: the next step in the minimally invasive approach to the spleen. Surg Innov. 2009;16:218-222.

21. Ujiki MB, Martinec DV, Diwan TS, Denk PM, Dunst CM, Swanstrom LL. Video: natural orifice translumenal endoscopic surgery (NOTES): creation of a gastric valve for safe and effective transgastric surgery in humans. Surg Endosc. 2010;24:220.

22. Fritscher-Ravens A, Ghanbari A, Cuming $\mathrm{T}$ et al. Comparative study of NOTES alone vs. EUS-guided NOTES procedures. Endoscopy. 2008;40:925-930.

23. Elmunzer BJ, Chak A, Taylor JR et al. Hydroperitoneum-facilitated EUS-guided peritoneal entry and closure of alternate access sites for NOTES. Surg Innov. 2010;17:101-107.

24. Sylla P. Current experience and future directions of completely NOTES colorectal resection. World J Gastrointest Surg. 2010;2:193198.

25. Sylla P, Rattner DW, Delgado S, Lacy AM. NOTES transanal rectal cancer resection using transanal endoscopic microsurgery and laparoscopic assistance. Surg Endosc. 2010;24:1205-1210.

26. Velhote MC, Velhote CE. A NOTES modification of the transanal pull-through. J Laparoendosc Adv Surg Tech A. 2009;19:255-257.

27. Leroy J, Diana M, Barry B et al. Perirectal Oncologic Gateway to Retroperitoneal Endoscopic Single-Site Surgery (PROGRESSS): a feasibility study for a new NOTES approach in a swine model. Surg Innov. 2012;19:345-352.

28. Elmunzer BJ, Schomisch SJ, Trunzo JA et al. EUS in localizing safe alternate access sites for natural orifice transluminal endoscopic surgery: initial experience in a porcine model. Gastrointest Endosc. 2009;69:108-114.

29. Swanstrom LL, Khajanchee Y, Abbas MA. Natural orifice transluminal endoscopic surgery: the future of gastrointestinal surgery. Perm J. 2008;12:42-47.

30. Flora ED, Wilson TG, Martin IJ, O'Rourke NA, Maddern GJ. A review of natural orifice translumenal endoscopic surgery (NOTES) for intra-abdominal surgery: experimental models, techniques, and applicability to the clinical setting. Ann Surg. 2008;247:583-602.

31. Delaney CP, Champagne BJ, Marks JM, Sanuk L, Ermlich B, Chak A. Tissue apposition system: new technology to minimize surgery for endoscopically unresectable colonic polyps. Surg Endosc. 2010;24:3113-3118.

32. Nikfarjam M, McGee MF, Trunzo JA et al. Transgastric naturalorifice transluminal endoscopic surgery peritoneoscopy in humans: a pilot study in efficacy and gastrotomy site selection by using a hybrid technique. Gastrointest Endosc. 2010;72:279-283.

33. de Sousa LH, de Sousa JA, de Sousa Filho LH et al. Totally NOTES (T-NOTES) transvaginal cholecystectomy using two endoscopes: preliminary report. Surg Endosc. 2009;23:2550-2555.

34. Swanstrom L, Swain P, Denk P. Development and validation of a new generation of flexible endoscope for NOTES. Surg Innov. 2009;16:104-110.

35. Swanstrom LL, Kozarek R, Pasricha PJ et al. Development of a new access device for transgastric surgery. J Gastrointest Surg. 2005;9:1129-36; discussion 1136-7.

36. Tessier C, Zhang L, Cao CG. Ergonomic considerations in natural orifice translumenal endoscopic surgery (NOTES): A case study. Work. 2012;41 Suppl 1:4683-4688.

37. Dunkin BJ. Natural orifice transluminal endoscopic surgery: Educational challenge. World J Gastrointest Surg. 2010;2:224-230.

38. Datta V, Mackay S, Mandalia M, Darzi A. The use of electromagnetic motion tracking analysis to objectively measure open surgical skill in the laboratory-based model. J Am Coll Surg. 2001;193:479-485.

39. Sachdeva AK, Pellegrini CA, Johnson KA. Support for simulationbased surgical education through American College of Surgeonsaccredited education institutes. World J Surg. 2008;32:196-207.

40. Al-Akash M, Boyle E, Tanner WA. Training on N.O.T.E.S.: from history we learn. Surg Oncol. 2009;18:111-119.

41. Fuchs KH, Breithaupt W, Kuhl HJ, Schulz T, Dignass A. Experience with a training program for transgastric procedures in NOTES. Surg Endosc. 2010;24:601-609.

42. Kavic MS, Mirza B, Horne W, Moskowitz JB. NOTES: issues and technical details with introduction of NOTES into a small general surgery residency program. JSLS. 2008;12:37-45.

43. Trunzo JA, Delaney CP. Natural orifice proctectomy using a transanal endoscopic microsurgical technique in a porcine model. Surg Innov. 2010;17:48-52.

44. Autorino R, White WM, Gettman MT et al. Public perception of "scarless" surgery: a critical analysis of the literature. Urology. 2012;80:495-502.

45. Bucher P, Ostermann S, Pugin F, Morel P. Female population perception of conventional laparoscopy, transumbilical LESS, and transvaginal NOTES for cholecystectomy. Surg Endosc. 2011;25:2308-2315.

46. Hucl T, Saglova A, Benes M et al. Patient and physician perception of natural orifice transluminal endoscopic appendectomy. World J Gastroenterol. 2012;18:1800-1805.

47. Peterson CY, Ramamoorthy S, Andrews B, Horgan S, Talamini M, Chock A. Women's positive perception of transvaginal NOTES surgery. Surg Endosc. 2009;23:1770-1774.

48. Benhidjeb T, Gericke C, Spies C, Miller K, Schneider A, Muller F. [Perception of natural orifice surgery. Results of a survey of female physicians and nursing staff]. Chirurg. 2011;82:707-713.

49. Ross SB, Hernandez JM, Sperry S et al. Public perception of LESS surgery and NOTES. J Gastrointest Surg. 2012;16:344-355.

50. Swanstrom LL, Volckmann E, Hungness E, Soper NJ. Patient attitudes and expectations regarding natural orifice translumenal endoscopic surgery. Surg Endosc. 2009;23:1519-1525.

51. Volckmann ET, Hungness ES, Soper NJ, Swanstrom LL. Surgeon perceptions of Natural Orifice Translumenal Endoscopic Surgery (NOTES). J Gastrointest Surg. 2009;13:1401-1410.

52. von Delius S, Meining A. Natural orifice transluminal endoscopic surgery (NOTES). Endoscopy. 2010;42:73-76. 
53. Mori H, Kobara H, Kobayashi $M$ et al. Establishment of pure NOTES procedure using a conventional flexible endoscope: review of six cases of gastric gastrointestinal stromal tumors. Endoscopy. 2011;43:631-634.

54. Lacy AM, Delgado S, Rojas OA, Almenara R, Blasi A, Llach J. MA-NOS radical sigmoidectomy: report of a transvaginal resection in the human. Surg Endosc. 2008;22:1717-1723.

55. Lacy AM, Saavedra-Perez D, Bravo R, Adelsdorfer C, Aceituno M, Balust J. Minilaparoscopy-assisted natural orifice total colectomy: technical report of a minilaparoscopy-assisted transrectal resection. Surg Endosc. 2012;26:2080-2085.

56. Lacy AM, Adelsdorfer C, Delgado S, Sylla P, Rattner DW. Minilaparoscopy-assisted transrectal low anterior resection (LAR): a preliminary study. Surg Endosc. 2013;27:339-346.

57. Franklin MEJ, Liang S, Russek K. Natural orifice specimen extraction in laparoscopic colorectal surgery: transanal and transvaginal approaches. Tech Coloproctol. 2013;17 Suppl 1:S63-7.

58. Franklin MEJ, Liang S, Russek K. Integration of transanal specimen extraction into laparoscopic anterior resection with total mesorectal excision for rectal cancer: a consecutive series of 179 patients. Surg Endosc. 2013;27:127-132.

59. Dostalik J, Gunkova P, Martinek L et al. [NOSE (Natural Orifice Specimen Extraction) in laparoscopic colorectal surgery]. Rozhl Chir. 2012;91:141-145.

60. Atallah S, Albert M, Larach S. Transanal minimally invasive surgery: a giant leap forward. Surg Endosc. 2010;24:2200-2205.

61. Atallah S, Albert M, Debeche-Adams T, Larach S. Transanal minimally invasive surgery (TAMIS): applications beyond local excision. Tech Coloproctol. 2013;17:239-243.

62. Albert MR, Atallah SB, deBeche-Adams TC, Izfar S, Larach SW. Transanal minimally invasive surgery (TAMIS) for local excision of benign neoplasms and early-stage rectal cancer: efficacy and outcomes in the first 50 patients. Dis Colon Rectum. 2013;56:301-307.

63. McLemore EC, Coker A, Jacobsen G, Talamini MA, Horgan S. eTAMIS: endoscopic visualization for transanal minimally invasive surgery. Surg Endosc. 2013;27:1842-1845.

\section{CME/MOC Questions - 8 multiple choice (A-D)}

1. All of the following are validated options for transgastric peritoneal entry in human patients except:

a. Endoscopic balloon dilatation

b. Sphincterotome

c. Needle knife cautery

d. EMR-cap myotomy
2. The transvisceral access approach with the highest morbidity is:

a. Transvaginal

b. Transvesical

c. Transgastric

d. Transanal

3. The first animal NOTES procedure described in the literature was: a. Transgastric liver biopsy

b. Transgastric cholecystectomy

c. Transvaginal appendectomy

d. Transvaginal colectomy

4. The first human NOTES procedure described in the literature was: a. Transrectal cholecystectomy

b. Transgastric cholecystectomy

c. Transvaginal appendectomy

d. Transrectal appendectomy

5. Feasibility studies of NOTES have shown all of the following except: a. No visible scars

b. Lower analgesia requirements

c. Low postoperative complication rates

d. Appropriate endoscopic instruments are available to safely facilitate each approach

6. The most commonly described access route for NOTES in human is:
a. Transvaginal
b. Transvesical
c. Transgastric
d. Transanal

7. Which is true regarding technical challenges to viscerotomy closure in NOTES?

a. The transvaginal approach risks injury to surrounding structures when closing the posterior vaginal wall

b. The transvesical approach is prohibitive in females due to their long urethra

c. The transrectal approach has eliminated the risk of closure leak and subsequent peritonitis.

d. Best practices for closure have been published by NOSCAR

8. Practical challenges to increase utilization of NOTES include:

a. Improving surgeon attitude

b. Improving public attitude

c. Developing a training platform to train providers to teach and use NOTES

d. All of the above 